\title{
Classifying Pretended and Evoked Facial Expressions of Positive and Negative Affective States using Infrared Measurement of Skin Temperature
}

\author{
MASOOD MEHMOOD KHAN \\ Curtin University of Technology \\ ROBERT D. WARD AND MICHAEL INGLEBY \\ University of Huddersfield
}

\begin{abstract}
Earlier researchers were able to extract transient facial thermal features from thermal infrared images (TIRIs) to make binary distinction between the expressions of affective states. However, affective human-computer interaction might require machines to distinguish between the subtle facial expressions of affective states. This work, for the first time, attempts to use the transient facial thermal features to recognise a much wider range of facial expressions. A database of 324 time-sequential, visible-spectrum and thermal facial images was developed representing different facial expressions from 23 participants in different situations. A novel facial thermal feature extraction, selection and classification approach was developed and invoked on various Gaussian mixture models constructed using: neutral and pretended happy and sad faces; faces with multiple positive and negative facial expressions; faces with neutral and six (pretended) basic facial expressions; and faces with evoked happiness, sadness, disgust and anger. This work demonstrates that (1) infrared imaging can be used to observe affective-state-specific thermal variations on the face; (2) pixel-grey level analysis of TIRIs can help localise significant facial thermal feature points along the major facial muscles; and (3) cluster-analytic classification of transient thermal features can help distinguish between the facial expressions of affective states in an optimized eigenspace of input thermal feature vectors. The observed classification results also exhibited influence of a Gaussian mixture model's structure on classifier-performance. The work also unveiled some pertinent aspects of future research on the use of facial thermal features in automated facial expression classification and affect recognition.
\end{abstract}

Categories and Subject Descriptors: I.4.2 [Image Processing and Computer Vision]: Application; I.5.2 [Pattern Recognition]: Design Methodology - Classifier design and evaluation, Feature evaluation and selection, Pattern analysis.

General Terms: Design, Experimentation

Additional keywords and Phrases: Physiology-based automated affect recognition, facial expression classification, affective computing and thermal infrared imaging.

\section{INTRODUCTION}

Ancient wisdom preserved in the classical literature, religious books, artifacts and fictionforms suggests some relationship between emotions and measurable human physiological information such as body temperature and facial blood volume flow (Crissey and Parish 2004). Common knowledge always suggested that emotions would generate several involuntary signals and cues in the human body: some of which were believed to be

Authors' addresses: Masood Mehmood Khan, Faculty of Science \& Engineering, Curtin University of Technology, GPO Box U1987, Perth, Western Australia 6845; Robert D. Ward, Department of Behavioral Sciences, University of Huddersfield, Queensgate, HD1 3DH, England; Michael Ingleby, School of Computing and Engineering, University of Huddersfield, Queensgate, HD1 3DH, England.

Permission to make digital/hard copy of part of this work for personal or classroom use is granted without fee provided that the copies are not made or distributed for profit or commercial advantage, the copyright notice, the title of the publication, and its date of appear, and notice is given that copying is by permission of the ACM, Inc. To copy otherwise, to republish, to post on servers, or to redistribute to lists, requires prior specific permission and/or a fee.

(c) 2008 ACM 
visible on the face as well. Modern scientific theories also support the common wisdom and suggest a direct relationship between emotions and autonomic response (Ekman 1982; Ekman et al. 1983; Ekman et al. 2000). The relationship between emotions and a variety of measurable bio-physiological signals has been reported in (Bradley et al. 2003; Dimberg, U. 1990a; Dimberg, U. 1990b; Palomba et al. 2000; Rimm-Kaufman and Kagan 1996; Sinha and Parson 1996; Wright et al. 2004). As reported in (Allanson and Fairclough 2004; Ang et al. 2004; Busso et al. 2004; Lisetti and Nasoz 2004), scientists were able to measure the bio-physiological and autonomic cues generated in response to the affective states. For example, in an investigation Sinha and Parson (1996) examined participants' heart rate, skin conductance level, finger temperature, blood pressure, electro-oculogram readings, and facial EMG recordings in neutral conditions, and in situations of anger, fear, joy, and sadness. They found that emotion-specific physiological response patterns to fear and anger were significantly different than those observed under the neutral condition. Ekman and others (1983) generated emotion-specific activity in the autonomic nervous system and observed that the produced autonomic activity could help in distinguishing between the positive and negative affective states. They could also discern between different negative emotions (Ekman et al. 1983; Zajonc 1985). Interestingly, studies suggest that not only humans but animals and birds also generate measurable autonomic and bio-physiological signals under emotive states (Nakayama et al. 2005; Olivier et al. 2003; Sarlo et al. 2005; Vianna and Carrive 2005).

The availability of human physiological information processing resources has enabled use of bio-physiological cues for clinical investigations, biometrics, security and surveillance, criminal investigation and human-computer interaction. More recently, some attempts were made to use the bio-physiological signals for automated recognition of affective states (Christie and Friedman 2004; Collet et al. 1997; Naemura et al. 1993; Pavlidis and Levine 2002; Pollina et al. 2006; Puri et al 2005). The detectable human information used to discern between the affective states included blood oxygen level dependent (BOLD) data, facial thermal features, skin temperature, electroencephalogram (EEG), electromyogram (EMG), electrooculogram (EOG), electrocardiogram (ECG), functional magnetic resonance imaging (fMRI) readings, blood pressure, respiratory patterns (RPNS) and galvanic skin response (GSR). Detailed discussion on underlying theories, implementation and potential application of physiology-based affect recognition systems is available in (Abidi et al 2004; Ang et al. 2004; Asthana and Mandal 1997; Boulic and Thalmann 1998; Critchley et al. 2000; DeSilva et al. 1997; Healey and Picard 2005; Jones et al. 1988; Khan et al. 2005; Lisetti and Nasoz 2004; Partala et al. 2006; Pavlidis 2004; Picard 2000; Pizzagalli et al. 1998; Posamentier and Abdi 2003; Prokoski 
and Iedel 1999; Puri 2005; Schwartz et al. 1976; Schwarz et al. 2002; Yoshitomi et al. 2000).

Scientists have discovered that emotion-specific patterns of variation in the facial thermal features would provide useful information about the affective states (Fujimasa 1998; Fujimasa et al. 2000; Jones 1998). In many studies, thermal infrared imaging could supplement Automated Facial Expression Classification (AFEC), Automated Affect Recognition (AAR) and face recognition (Bolle 2004; Kakadiaris et al. 2005a; Kakadiaris et al. 2005b; Khan et al. 2004; Kong et al. 2005; Kunzmann and Gruhn 2005; Kurse 2001; Matsuzaki and Mizote 1996; McGimpsey et al. 2000; Ogasawara et al. 2001). Human skin temperature, a bio-physiological signal, could be acquired through noncontact means and used in AFEC and AAR systems. Thermal infrared imaging, a noninvasive technology, was used to measure the skin thermal features related transient information in these AFEC and AAR systems (Khan 2008; Khan et al 2006; Pavlidis 2004; Puri et al. 2005; Sugimoto et al. 2000; Yoshitomi et al. 2000). However, the existing literature does not provide authoritative answers to the following questions:

1. Is it possible to measure the emotion-specific transient facial thermal features under a wide range of social situations in a non-invasive manner?

2. Do the emotion specific transient facial thermal features help recognize a wide range of underlying affective states? For example, would it be possible to distinguish between the six basic affective states, proposed by Ekman (1982), using the emotion-specific transient facial thermal features?

3. Is it possible to use the transient facial thermal variations for developing a reliable AFEC and AAR capable system?

4. Do the transient facial temperature variations help in classifying the facial expressions of affective states along the direction of valance?

5. Do the thermal profiles of pretended and evoked facial expressions differ?

6. Would the underlying differences in the thermal profiles of pretended and evoked facial expressions influence the performance of a physiological information supported classifier?

In order to find reliable answers to above questions, we began by acquiring thermal data from 16 participants' faces when they acted and simulated six basic (positive and negative) facial expressions. Also, the thermal data were separately acquired from 10 participant faces when emotions were evoked. A novel feature extraction, selection and classification algorithm was developed and invoked for constructing the classifier. Our work provides more reliable answers to the above questions. So, the results of this investigation provide scientific foundations of thermal sensing of affective states. 
We report previous related work in section 2. Details of the employed thermal data acquisition tools and methods are reported in section 3. Section 4 presents our algorithmic approach. Classification results are reported and analyzed in section 5. The performance of various classifiers is compared in section 6. The work is concluded in section 7 and the future work directions are proposed in section 8 .

\section{PREVIOUS WORK}

Scientists assert that certain real life situations and emotional conditions cause changes in the blood volume flow. The increased blood brought under a particular area of skin as a result of stress is called reactive hyperemia. Studies suggest that a change in affective state would also cause hyperemia. Thermal infrared imaging has been used to diagnose hyperemia and monitor and quantify the effects of dynamic stress on the skin (McGimpsey et al. 2000; Nakayama 2005; Ogasawara et al. 2001; Phillips 2002). Application of thermal infrared imaging in relevant areas has been reported in the literature (Eveland et al. 2003; Fujimasa 1998; Fujimasa et al. 2000; Herry and Frize 2002; Jones and Plassmann 2002; McGimpsey et al. 2000; Nakayama et al. 2005; Ogasawara et al. 2001; Pavlidis 2004; Prokoski and Iedel 1999; Socolinsky et al 2003; Sugimoto et al. 2000). Earlier researchers have also used infrared imaging of skin thermal features to recognize facial expressions and affective states (Khan et al. 2006; Kim et al. 2004; Pavlidis 2004; Pavlidis and Levine 2002; Puri et al. 2005; Sugimoto et al. 2000; Yoshitomi et al. 2000).

In a recent work, thermal facial screening was employed to detect attempted deceit (Pavlidis 2004). Sugimoto and others (2000) used thermal images to detect transitions of affective states through the synthesis of facial expressions. Yoshitomi and other (2000) used a combination of visual images, thermal features and audio signals for recognizing affective states. The resulting integrated signal classifier could, on the average, perform with 85\% accuracy (Yoshitomi et al. 2000). Kim and others (2004) developed a physiological signal based emotion recognition system. Fusion of electrodermal activity data, electrocardiogram readings and the skin temperature measurements were used to classify the emotions. A support vector machine adopted for pattern classification could achieve up to $78.4 \%$ classification accuracy (Kim et al. 2004). Puri and others (2005) reported development of a system for non-contact measurement of emotional states using thermal infrared imaging. They reported that users' stress level was correlated with increased blood flow in the frontal vessels of forehead and caused the dissipation of convective heat (Puri et al. 2005). Another recent study discovered that the facial skin surface temperature would undergo significant changes during a concealed information 
test (Pollina et al 2006). Jiang and Le (2007) were able to discover and measure a significant variation in the facial skin temperature with a change in facial expression.

In a related investigation, the viability of using infrared measurements of facial skin temperature for recognizing the pretended facial expression of affective states was explored (Khan et al. 2006). The investigators were able to successfully classify $66.28 \%$ thermal images during the cross-validation tests and $56.0 \%$ thermal images during a person-independent test. In concluding their work, the investigators noted that in a real life scenario, the AFEC systems would work on naturally occurring, spontaneous, and evoked or reactive facial expressions and realized the need for classifying the facial expressions with naturally evoked emotions (Khan et al. 2006).

Earlier works and relevant literature suggest that facial skin temperature measurements might assist in achieving the AFEC and AAR functionality. The cited investigations also reported availability of appropriate computational methods for infrared image processing and bio-physiological pattern analysis.

\section{FACIAL SKIN TEMPERATURE MEASUREMENT AND DATA ANALYSIS}

Experimental work for this research was carried out at the American University of Sharjah. The infrared images were acquired under neutral, controlled and comfortable building environment. Internal temperature of rooms used for conducting experiments varied between $19-22{ }^{\circ} \mathrm{C}$ during the data acquisition. The building air conditioning system was equipped with humidity controller and air recycling system. Each participant was given at least 20 minutes to acclimatize with the environment.

A CANTRONIC IR860 thermal infrared camera equipped with a special storage disk and data transfer peripherals, was used in this investigation (Cantronic 2001).

\subsection{Participants and human protection practices}

Initially, 16 undergraduate students, 12 men and 4 women, with a mean self-reported age of 20 years 9 months volunteered for the experiments. The participants were adults and included Africans, Caucasians, Arabs, Iranians, Indians and Pakistanis. The thermal data acquired from these 16 participant faces were used for developing a classifier to recognize and classify the pretended facial expressions.

At a later stage, 10 students, 7 men and 3 women with a self-reported mean age of 21 years 2 months volunteered for the experiments. The data acquired from these participant faces were used for developing the evoked expression classifier. Only 3 of the 10 men also participated in the previous experiment when pretended facial expressions were recorded. 
Ethical principles and guidelines for the protection of human participants of biomedical and behavioral research outlined in the Belmont report (Belmont report 1979; DHEW1979) were observed during the experiments. Experiment design practices and protocols were explained to the participants at the beginning of each image acquisition session. Efforts were made to protect participant from any physical and/or emotional harm and damage.

\subsection{Thermal image acquisition}

The thermal and visible spectrum images of each participant were simultaneously recorded. After neutral faces were captured, participants' images with facial expressions of happiness, sadness, surprise (positive), disgust and anger were recorded. Figure 1 shows a set of visible spectrum images, thermal infrared images and their corresponding thermograms. As evident from the varying patterns of thermal measurements within the ellipses in Figure 1, the thermograms change with a change in facial expression.

Thermal data for evoked facial expressions were recorded at a later stage. Several methods of evoking and stimulating emotions and affective states have been reported in the literature on Psychology and Cognitive Studies (Dror et al. 2005; Murphy and Zajonc 1993; Niedenthal et al. 2000; Wild et al. 2001). Some widely used methods of evoking emotions include affective picture viewing, emotive text reading and storytelling (Partala et al. 2006; Whiteside 1998). Participants in (Dror et al. 2005; Toivanen 2004; Wild et al. 2001) were exposed to one or more of these stimuli for invoking the desired positive and negative emotions.

We selected a set of still images and video clips for stimulating the emotions. The media selected for stimulating the affective states were examined to see if they meet the guidelines provided in the University of Florida's International Affective Picture System (IAPS) instruction manual (IAPS 1997). This ensured proper stimulation of affective states and their facial expressions and guaranteed that the contents of our employed stimuli were no more extreme that those shown on mainstream television news and feature stories. The emotion stimulating resources were available on the official web sites of prestigious publishers such as BBC, MSNBC, and CNN.

\subsection{Thermal infrared image processing}

Pixel grey-levels extracted from a thermal image provide a measure of the response of the detector element (such as the microbolometer arrays installed on the employed IR 860 thermal camera) to the infrared radiant power absorbed. The radiant power falling on the detector element is considered a function of the radiance of the surface and the solid 
angle subtended by the exit pupil of the thermal camera. The solid angle, by the virtue of camera design, remains constant allowing the grey-levels to change with any changes in the radiance of the object surface (Jones and Plassmann 2002; Otsuka et al. 2002).

\section{FIGURE 1 HERE}

Figure 1: Visible and infrared images with corresponding thermograms of a participant. From left to right: neutral face, pretended happiness, and sadness

Infrared cameras operate in a temperature range of -20 to $500{ }^{\circ} \mathrm{C}$. Depending upon the bit-depth, between 4096-16384 grey levels of pixels represent the extreme temperature points in a thermogram. A grey-level of zero corresponds to the lowest temperature and the highest level of grey corresponds to the highest temperature in a thermal image (Jones and Plassmann 2002). The camera temperature range in this investigation was set between $0-40{ }^{\circ} \mathrm{C}$ during the image acquisition hence the grey-level of 0 corresponded to 0 ${ }^{\circ} \mathrm{C}$ and the highest grey-level corresponded to the highest facial skin temperature observed in an acquired facial thermal infrared image.

To avoid any undesired noise in the acquired thermal images and to have accurate thermal measurements, the thermal images are usually enhanced before extracting the pixel grey level information. The "median smoothing filter" recognized as one of the best order-statistic filter (Gonzalez and Woods 2002), was invoked on the thermal images for blurring and noise reduction. The filter replaces value of a pixel by the median of the grey levels in the neighborhood of the pixel as

$$
\hat{f}(p, q)=\operatorname{median}_{(s, t) \in S_{p q}}\{k(s, t)\}
$$

where $\hat{f}(p, q)$ is the median filter that replaces the value of a pixel $(s, t)$ by the median of the grey levels within a neighborhood.

In a following image processing step, the Sobel operator-based edge detection algorithm was invoked for extracting the contours within the infrared images. The Sobel operator is basically a neighborhood-based gradient operator. Two convolution masks for the Sobel operator are separately applied on the input facial image to yield the two gradient components $G s$ and $G t$ in the horizontal and vertical directions. The neighborhood kernels define the convolution masks. For the selected $3 \times 3$ neighborhood the gradient operators were calculated as (Acharya and Ajoy 2005; Gonzalez and Woods 2002):

$$
\begin{gathered}
G s=[f(i-1, j-1)+2 f(i-1, j)+f(i-1, j+1)]-[f(i+1, j-1)+2 f(i+1, j)+f(i+1, j+1)] \\
\text { and } G t=[f(i-1, j-1)+2 f(I, j-1)+f(i+1, j-1)]-[f(i-1, j+1)+2 f(I, j+1)+f(i+1, j+1)] .
\end{gathered}
$$


The gradient magnitude was computed as

$G[f(s, t)]=\sqrt{G_{s}^{2}+G_{t}^{2}}$.

\subsection{Emotion-specific facial skin temperature variation measurement}

The literature cites several methods of acquiring data pertaining to thermo-physiological processes in skin regions (Garbey et al. 2004; Pavlidis 2000; Sugimoto et al. 2000; Yoshitomi et al. 2000). Our facial thermal features extraction approach was based on the assumption that an infrared image with a "neutral face" would be (thermally) different from the ones exhibiting the facial expressions of affective states. Initially, attempts were made to observe any variation in the thermal intensity values on different parts of the face with a change in facial expression. This allowed exploring the relationship between the facial expression and variations in thermal intensity values in local facial regions. The resulting facial thermal representation was based on local thermal features. This approach was similar to the one used to develop a typical local-feature based model widely used in vision-based AFEC systems. Our initial results suggested that the local-feature based approach might not be suitable for representing the facial thermal features. Thus the need for a different approach was realized.

We intended to keep the independence between the acquired thermal data $\left(\right.$ Correlation $\left._{\min }\right)$ and maintain the symmetry of variance-covariance structure (Variance ${ }_{\max }$ ) between the facial expression groups. To achieve the two objectives, the thermal infrared images were repeatedly divided into an increasing number of square segments and the thermal variations within these square segments were recorded. After repeated thermal analyses of infrared images, the Facial Thermal Feature Points (FTFPs) that allowed achieving the two objectives were discovered at 75 locations along the major facial muscles.

Figure 2 shows these 75 FTFPs on a neutral human face and a muscular map of the human face. The FTFPs and their muscular alignments are listed in Table 1.

\section{FIGURE 2 HERE}

Figure 2: From left: the facial thermal feature points (FTFPs) on a human face and

on the human facial muscle map

TABLE 1: FACIAL THERMAL FEATURE POINTS AND THEIR MUSCULAR ALIGNMENT

\begin{tabular}{|l|l|}
\hline \multicolumn{1}{|c|}{ Facial Muscle } & Facial Thermal Feature Points (FTFPs) \\
\hline Frontalis, Pars Medialis & $1,3,6,8,13,15$ \\
\hline Frontalis, inner center edges of pars medialis and pars lateralis & 2,7 \\
\hline Frontalis, Pars Lateralis & $4,5,9,10,11,12,16,17$ \\
\hline
\end{tabular}




\begin{tabular}{|l|l|}
\hline Procerus/ Levator, Labii Superioris Alaquae Nasi & 21 \\
\hline Depressor, Supercilii & 14 \\
\hline Orbicularis Oculi, Pars Orbital & $18,19,20,22,23,24,25,26,27,29,30,31$ \\
\hline Orbicularis Oris & $45,51,64,65,66$ \\
\hline Levator, Labii Superioris Alaquae Nasi & $28,35,36$ \\
\hline Levator, Labii Superioris & $33,34,37,38,44,46$ \\
\hline Masseter, Superficial & $40,41,49,50$ \\
\hline Levator, Anguli Oris & 43,47 \\
\hline Zygomaticus Major & $32,39,42,48$ \\
\hline Risorious/ Platysma & $52,53,54,59,60,61$ \\
\hline Depressor Anguli Oris & 55,58 \\
\hline Buccinator & 56,57 \\
\hline Platysma & $62,63,67,68$ \\
\hline Depressor Labii Inferioris & $69,70,71,72$ \\
\hline Mentalis & $73,74,75$ \\
\hline
\end{tabular}

TABLE 2: PHYSICAL LOCATION OF FTFPS ON THE FACE

\begin{tabular}{|l|l|}
\hline \multicolumn{1}{|c|}{ Part of the face } & \multicolumn{1}{c|}{ FTFPs } \\
\hline Forehead & $1,2,3,4,5,6,7,8,9,10$ \\
\hline Around the eyes & $11,12,13,14,15,16,17,18,19,20,21,22,23,24,25,26,27,28,29,30,31$ \\
\hline Cheeks & $32,33,34,35,36,37,38,39,40,41,42,43,47,48,49,50,62,63$ \\
\hline Around mouth & $44,45,46,51,52,53,54,55,56,57,58,59,60,61,64,65,66$ \\
\hline Chin & $67,68,69,70,71,72,73,74,75$ \\
\hline
\end{tabular}

It is obvious from Table 1 that more than 50 percent of these FTFPs are located on 5 major facial muscles: Frontalis (16 FTFPs), Orbicularis Oculi Pars Orbital (12 FTFPs), Levator Labii Superioris (6 FTFPs) and Risorious (6 FTFPs). Figure 3 shows the frontal view of a facial thermal map. A close examination of figures 2 and 3 suggests that FTFPs are located along those major facial muscles, which undergo significant movement with a change in facial expression. It was interesting to note that the FTFPs were discovered all over the face as 10 FTFPs were found on the forehead, 21 around the eyes, 18 on the cheek, 17 around mouth and 9 on the chin. Table 2 shows physical location of FTFPs on the major anatomical parts of the face.

\subsection{Initial analyses of transient facial skin temperature data}

The measured Thermal Intensity Values (TIV) data were examined for normal distribution and symmetry of variance in the data pertaining to various facial expressions groups. The TIV data were found normally distributed and the facial expression groups had similar variance-covariance structures. The number of participants in each facial expression group was same.

\section{FIGURE 3 HERE}

Figure 3: Frontal view of the facial muscles showing physical location of major facial muscles on a human face

FIGURE 4 HERE 
It was therefore safe to assign an equal a priori for group membership during the subsequent analyses (Duda et al. 2001; Jolliffe 2002; Kinnear and Gray 2000; McLachlan 2004).

\section{THERMAL FEATURE EXTRACTION, SELECTION AND CLASSIFICATION}

Pattern analysis methods such as Artificial Neural Network (ANN), Support Vector Machines (SVM), Linear Discriminant Analysis (LDA), K-nearest Neighbor (KNN), Logistic Regression (LR), Hidden Markov Model (HMM), Naïve Bayes Classifier and Principal Components Analysis (PCA) have been used for face recognition, facial expression classification and affect recognition (Bartlett et al. 1999; Chen and Huang 2003; Essa and Pentland 1997; Tian et al. 2002).

Based on an extensive literature review, a computational approach exhibited in Figure 4 and explained in the following paragraphs was developed.

\subsection{Facial thermal feature extraction}

In order to extract the facial thermal features using the principal component analysis, each thermal image was considered a $p$-dimensional random facial thermal vector $\mathbf{x}$. There were $n$ such thermal feature vectors, $\mathbf{x}_{\mathbf{i}},(i=1,2, \ldots, n)$ having $p$ TIV measurements in the learning set. Each thermal vector could be represented as $\mathbf{x}_{\mathbf{i}}=\left[x_{i 1}, x_{i 2} \ldots, x_{i p}\right]^{T}$. The TIV data were standardised to draw a learning set $G_{0}=\left[\mathbf{x}_{1}\left|\mathbf{x}_{2}\right| \ldots \mid \mathbf{x}_{n}\right]$ containing the $n$ number of $p$-dimensional facial thermal vectors. The mean facial thermal vector $\overline{\mathbf{x}}$ of the learning set was obtained as:

$$
\overline{\mathbf{x}}=\frac{\mathbf{1}}{\mathbf{n}} \sum_{n=1}^{n} \mathbf{x}_{\mathbf{i}}
$$

The mean facial thermal vector $\overline{\mathbf{x}}$ was subtracted from each random facial thermal vector present in the data set to find its difference $\tilde{\mathbf{x}}_{\mathbf{i}}$ from $\overline{\mathbf{x}}$ as

$$
\tilde{\mathbf{x}}_{\mathbf{i}}=\mathbf{x}_{\mathbf{i}}-\overline{\mathbf{x}} \text {. }
$$

After off setting in this way, the learning set was presented as a $p \times n$ matrix $G=\left[\tilde{\mathbf{x}}_{1}\left|\tilde{\mathbf{x}}_{2}\right| \ldots \mid \tilde{\mathbf{x}}_{n}\right]$.

The $p \times p$ covariance matrix of the learning set was thus

$$
C=G G^{T} \text {. }
$$

The covariance matrix $C$, being symmetric and positive-definite was reducible to the form 


$$
C=H_{l} D H_{l}^{T}
$$

Where the linear transformation matrix $H_{l}$ is an orthogonal non-zero eigenvector matrix of $C$ and is represented as columns of eigenvectors

$$
H_{l}=\left[v_{1}\left|v_{2}\right| \ldots \mid v_{p}\right]
$$

The face recognition and facial expression classification literature often refers to the eigenvectors $v_{i}[i=1,2, \ldots, p]$ as eigenfaces, and we follow this nomenclature The matrix $D$ in Equation E-8 is the corresponding diagonal eigenvalue matrix of $H_{l}$ such that

$$
D=\operatorname{diag}\left[\lambda_{1}, \lambda_{2}, \ldots, \lambda_{p}\right]
$$

The diagonal elements of the eigenvalue matrix $D$ are arranged in a descending order as $\left[\lambda_{1} \geq \lambda_{2} \geq \ldots \geq \lambda_{p}\right]$. Arranging eigenvectors in this order shows the most important and largest directions of the variance in the data set. By removing the lowest eigenvalues from $D$, and the corresponding columns from the transformation matrix $H_{l}$, suitable datareduction is achieved, reducing the thermal feature vector space to a span of only $M$ eigenfaces $(M<<p)$.

The learning set $G$ in this work was pre-classified so it was easy to group together the facial thermal feature vectors into $g$ number of facial expression clusters. Thus, the data set $G$ could be regarded as a disjoint union of $g$ facial expression groups such that

$$
G=G_{1} \cup G_{2} \cup \ldots \cup G_{g} .
$$

By arrangement, $\mathrm{n}_{j}$ samples of a face with expression $j$ were included in the group $\mathrm{G}_{j}$. Hence the statistical model of the data set $G$ could be assumed to take the form

$$
\tilde{x}_{i j k}=\mu_{i}+\tau_{i j}+\varepsilon_{i j k} ;\left(1 \leq j \leq p, 1 \leq j \leq g, 1 \leq k \leq n_{j}\right)
$$

In Equation E-12, $\tilde{x}_{i j k}$ is the $i^{\text {th }}$ observation for a face expressing emotive state $j$ and is the $k^{\text {th }}$ such face with this expression, $\mu_{i}$ is the mean value of all observations at point $i, \tau_{i j}$ represents the offset of the centre of the $j^{\text {th }}$ cluster from $\mu_{i}$ and $\varepsilon_{i j k}$ is a residual that is minimised while estimating the other model parameters from the data set. This model can be generalised to represent the expression of an affective state as multiple clusters if some variations are bimodal or of higher modality. However, the small sample of facial thermal images used in this work had no multi-modal variations and did not require such a generalisation.

\subsection{Optimal facial thermal feature selection}

We iteratively discovered a subset of $M$ best discriminating PCs from within the set $\left\{\zeta^{(l)} \mid l=1, \ldots, p\right\}$ of the PCs. The method is based on the stepwise test process in which less effective PCs are eliminated step by step and only the best discriminating PCs are 
retained in an optimized subspace. The process begins with all PCs ranked by size of a Fisher ratio for the distribution of components $x_{i j k}$. The $\zeta^{l)}$ of training sample observations projected along the $\zeta^{(l)}$ direction. These distributions have variances $S^{(l)}$, which are sums of a between-cluster part $S_{W}{ }^{l}$, and a within-cluster part $S_{B}{ }^{l}$. The Fisher ratio for $\zeta^{(l)}$ is given by $F^{(l)}=S_{B}^{l} / S_{W}^{l}$ and is greater for the PCs that better discriminate between the clusters. A similar ratio can be defined for subspaces E spanned by several PCs, except that the variances $S^{(E)}, S_{W}{ }^{(E)}$, and $S_{B}^{(E)}$ generalize to square matrices. For such an $E$, the Fisher ratio, $F^{(E)}$, can be defined as the ratio of determinants $S_{B}^{(l)}$, and $S_{W}^{(l)}$ of these variance matrices. Then the optimized subspace that our procedure seeks out can be expressed as

$$
M=\operatorname{argmax}_{E}\left\{F^{(E)}\right\},
$$

where $E$ varies over all possible spans of two, three or more PCs, and $M$ is the argument of function $F^{(E)}$ that corresponds to the maximum value of the function. Our procedure approaches this subspace via a sequence $M_{1}, M_{2}, M_{3}, \ldots M_{n}$ starting with the 1 dimensional space spanned by the most discriminating PCs. Having reached, using at least the $n$ most discriminating PCs to span an $n$-dimensional $M_{n}$ with Fisher ratio $F_{n}$, the next space $M_{n+1}$ is formed by considering the next-most discriminating PC, $\zeta^{(l)}$, and the test span $T$ formed by this and $M_{n}$. If $F^{(T)}$ exceeds $F_{n}$, then $T$ is a better approximation to optimal $M$ than $M_{n}$ and we take $M_{n+1}=T$; otherwise we retain $M_{n}$ and take a new $\zeta^{(l)}$ and form a new test span $T$. Finding optimal PCs using Fisher's criterion is an established and well-tested approach (McLachlan 2004; Webb 2002), and we adapted it to solve the classification problem in hand. Figure 5 exhibits the algorithmic implementation of our optimal feature selection method.

\subsection{Facial thermal feature Classification}

After PCA of a training sample, the use of linear discriminants (LDA) has been successful in several related investigations. Typically, a linear discriminant is a hyperplane that separates optimally a cluster of the training sample from the rest of the sample (Jolliffe 2002). With $J$ affect clusters, the resulting $J$ hyperplanes partition the observation space into $2^{J}$ regions bounded by hyperplanes, of which $J$ contain only one cluster centre, ${ }^{J} C_{2}$ contain 2 centres, ${ }^{J} C_{3}$ contain 3 , and so on. A new thermal image vector can be 'classified' by assigning it to one region, but if the region contains several centres the classification is ambiguous.

For lifting the ambiguity, a distance or similarity criterion is needed: it must assign the new vector to the nearest or most similar cluster centre in the region. In this work we 
used the Mahalanobis distance, defined in terms of the pooled within-cluster variance matrix, $W$, of a training sample. If the $x-x_{j}$ is the vector joining new image vector to the centre of cluster $j$, then the Euclidean length $\left\|\left(x-x_{j}\right) W^{l}\right\|$ defines the Mahalanobis distance from $x$ to cluster $j$.

\section{FIGURE 5 HERE}

Figure 5: The optimal feature selection algorithm

Thus, the nearest cluster to $\mathrm{x}$ in a region containing several cluster centres is given by $\operatorname{argmin}_{\mathrm{j}}\left\{\left\|\left(x-x_{j}\right) W^{l}\right\|\right\}$. This way of developing the discriminant rules in a classification problem has a long history (Everitt and Dunn 1991; McLachlan 2004). We implemented it as a critical foil to our optimized subspace method, operating in a subspace spanned by all the PCs of training samples that contribute more than $1 \%$ to total variance measured by the trace of $D$.

\section{CLASSIFICATION RESULTS}

First, an attempt was made to classify the neutral, pretended happy and sad facial expressions. Table 3 shows the confusion matrix obtained when optimal principal components were used for discriminating between the three facial expressions.

In a following analysis, a classifier was developed to classify two positive (happy and surprise) and two negative (disgust and anger) facial expressions Table 4 shows the confusion matrix and the observed classification results.

TABLE 3: ClassificAtion RESUlts FOR NEUTRAL, AND PRETENDED HAPPY AND SAD FACIAL EXPRESSIONS

\begin{tabular}{|c|c|c|c|c|c|}
\hline \multirow[t]{2}{*}{ Classification } & \multirow{2}{*}{$\begin{array}{c}\text { Facial } \\
\text { expression }\end{array}$} & \multicolumn{3}{|c|}{ Predicted Group Membership } & \multirow[t]{2}{*}{ Total } \\
\hline & & Neutral & Happy & Sad & \\
\hline \multirow{3}{*}{$\begin{array}{c}\text { Cross-validation }^{a, b} \\
(\%)\end{array}$} & Neutral & 81.3 & 6.3 & 12.5 & 100.0 \\
\hline & Happy & 0 & 87.5 & 12.5 & 100.0 \\
\hline & Sad & 6.3 & 12.5 & 81.3 & 100.0 \\
\hline
\end{tabular}

TABLE 4: CLASSIFICATION RESULTS FOR FOUR PRETENDED FACIAL EXPRESSIONS

\begin{tabular}{|c|c|c|c|c|c|c|}
\hline \multirow[t]{2}{*}{ Classification } & \multirow{2}{*}{$\begin{array}{c}\text { Facial } \\
\text { expression }\end{array}$} & \multicolumn{4}{|c|}{ Predicted Group Membership } & \multirow[t]{2}{*}{ Total } \\
\hline & & Happy & Disgust & Surprise & Angry & \\
\hline \multirow{4}{*}{$\begin{array}{c}\text { Cross- } \\
\text { Validated } \\
\text { cases }^{a, b}(\%)\end{array}$} & Happy & 62.5 & 6.3 & 31.3 & 0 & 100.0 \\
\hline & Disgust & 6.3 & 56.3 & 18.8 & 18.8 & 100.0 \\
\hline & Surprise & 6.3 & 6.3 & 87.5 & 0 & 100.0 \\
\hline & Angry & 6.3 & 18.8 & 12.5 & 62.5 & 100.0 \\
\hline
\end{tabular}

TABLE 5: CLASSIFICATION OF NEUTRAL AND SIX BASIC FACIAL EXPRESSIONS

\begin{tabular}{|c|c|c|c|c|c|c|c|c|}
\hline $\begin{array}{c}\text { Classification } \\
(\text { Cross } \\
\begin{array}{c}\text { Validation } \\
\text { results(\%) }\end{array}\end{array}$ & Neutral & Happy & Sad & Disgust & Surprise & Angry & Fear & \\
\cline { 2 - 7 }
\end{tabular}




\begin{tabular}{|c|c|c|c|c|c|c|c|c|}
\hline Neutral & 31.3 & 12.5 & 18.8 & 12.5 & 18.8 & 6.3 & 0 & 100.0 \\
\hline Happy & 12.5 & 62.5 & 0 & 0 & 18.8 & 0 & 6.3 & 100.0 \\
\hline Sad & 25.0 & 0 & 68.8 & 0 & 0 & 6.3 & 0 & 100.0 \\
\hline Disgust & 12.5 & 6.3 & 0 & 62.5 & 0 & 6.3 & 12.5 & 100.0 \\
\hline Surprise & 18.8 & 0 & 12.5 & 6.3 & 43.8 & 12.5 & 6.3 & 100.0 \\
\hline Angry & 18.8 & 18.8 & 0 & 0 & 6.3 & 43.8 & 12.5 & 100.0 \\
\hline Fear & 0 & 6.3 & 0 & 0 & 6.3 & 0 & 87.5 & 100.0 \\
\hline
\end{tabular}

TABLE 6: CLASSIFICATION RESULTS FOR EVOKED FACIAL EXPRESSIONS

\begin{tabular}{|c|c|c|c|c|c|c|c|}
\hline \multirow[t]{2}{*}{ Classification } & \multirow{2}{*}{$\begin{array}{c}\text { Facial } \\
\text { expression }\end{array}$} & \multicolumn{5}{|c|}{ Predicted Group Membership } & \multirow[t]{2}{*}{ Total } \\
\hline & & Neutral & Happy & Sad & Disgust & Angry & \\
\hline \multirow{5}{*}{$\begin{array}{c}\text { Cross- } \\
\text { Validated } \\
\text { cases }^{a, b}(\%)\end{array}$} & Neutral & 70.0 & 0 & 0 & $\frac{10}{10.0}$ & 20.0 & 100.0 \\
\hline & Happy & 0 & 70.0 & 20.0 & 10.0 & 0 & 100.0 \\
\hline & Sad & 0 & 10.0 & 90.0 & 0 & 0 & 100.0 \\
\hline & Disgust & 10.0 & 10.0 & 0 & 70.0 & 10.0 & 100.0 \\
\hline & Angry & 20.0 & 0 & 0 & 20.0 & 60.0 & 100.0 \\
\hline
\end{tabular}

In the next analysis, another classifier was developed to classify neutral and six basic facial expressions. Table 5 shows the confusion matrix and the observed classification results.

Finally, an attempt was made to classify the neutral and evoked facial expressions of happiness, sadness, disgust and anger. Table 6 shows the confusion matrix obtained when the optimal principal components were used for discriminating between the neutral faces and faces with evoked facial expressions.

The discriminant analysis algorithm resulted in four discriminant functions to distinguish between the neutral faces and the faces with evoked facial expressions.

The first discriminant function apparently compared the thermal features on the selected sites around the upper and lower parts of the face for classifying new and unknown thermal faces.

The second discriminant function relied on the variates measured at Frontalis, Orbicularis Oculi Pars Orbital, Levator Labii Superioris Alaquae Nasi, Levator Labii Superioris, Zygomaticus Major, Risorious/ Platysma, Depressor Anguli Oris and Mentalis for recognition and classification of new and unknown faces.

The third discriminant function relied on variates measured at several locations on Frontalis, Orbicularis Oculi Pars Orbital, Masseter Superficial, Zygomaticus Major, Levator Labii Superioris, Depressor Anguli Oris, Depressor Labii Inferioris and Mentalis for allocating unknown thermal faces to one of the evoked facial expression groups.

The fourth discriminant function relied on the variates measured at on Frontalis, Frontalis Pars Medialis, Orbicularis Oculi Oars Orbital, Levator Labii Superioris, Zygomaticus Major, Levator Labii Superioris Alaquae Nasi, Levator Anguli Oris, 
Risorious/ Platysma, and Platysma for allocating unknown thermal faces to either the neutral or to one of the evoked facial expression groups.

Given the small sample size and a large number of measured variables (thermal intensity values), the overall error rate $e_{\text {general }}^{j}(=28.0 \%)$ observed during the leave-oneout cross validation tests looks highly encouraging.

\section{CLASSIFIER PERFORMANCES AND CLASSIFICATION ERROR ANALYSIS}

Table 8 compares various classifiers developed during this investigation. When the discriminant space was constructed using the thermal data from the neutral faces and the faces with intentional happy and sad expressions (row 2 of Table 8), 83.3\% success rate was observed. When the thermal data measured on the neutral faces and faces with intentional happy, disgusted, surprised and angry expressions were used for constructing the discriminant space (row 3 of Table 8), the complexity of the discriminant space further increased and probably caused an even lower classification success rate $(67.2 \%)$. The discrimination space got more complex when a neutral and six pretended basic facial expressions were classified (row 4 of Table 8). A very low classification success rate $(57.1 \%)$ was observed.

We use a comparison of the observed classification and confusion patterns to understand the differences and similarities between the measured thermal features pertaining to various evoked and intentional facial expressions.

When the discriminant space was constructed using the thermal data measured on the neutral faces and the faces with four evoked expressions (last row of Table 8), the classifier performed at $72 \%$ success rate. As evident in Table 8 , the five evoked expression classifier (last row of Table 8) performed better than the four intentional expressions classifier (row 3 of Table 8). This difference in the classifier performance suggests that the classification results do not completely depend upon the complexity of the given discriminant space.

TABLE 8: CONSTRUCTION OF THE DISCRIMINANT SPACE, EMPLOYED TRAINING FEATURES AND THE CLASSIFIER PERFORMANCE

\begin{tabular}{|c|l|l|}
\hline $\begin{array}{c}\text { Facial expressions used for } \\
\text { constructing the discriminant space }\end{array}$ & $\begin{array}{c}\text { Training features } \\
\text { employed }\end{array}$ & $\begin{array}{c}\text { Overall classification } \\
\text { success rate observed }\end{array}$ \\
\hline $\begin{array}{c}\text { Neutral and Intentionally happy and sad } \\
\text { expressions }\end{array}$ & $\begin{array}{c}\text { Optimal features recursively drawn from } \\
\text { among the derived principal components }\end{array}$ & $83.3 \%$ \\
\hline $\begin{array}{c}\text { Intentional happy, disgust, Surprise and } \\
\text { angry expressions }\end{array}$ & - same as above - & $67.2 \%$ \\
\hline $\begin{array}{c}\text { Neutral and six pretended basic facial } \\
\text { expressions }\end{array}$ & - same as above - & $57.1 \%$ \\
\hline $\begin{array}{c}\text { Neutral and Evoked happy, sad, disgust, } \\
\text { and angry expressions }\end{array}$ & - same as above - & $72.0 \%$ \\
\hline \multicolumn{2}{|c|}{} & \\
\hline
\end{tabular}


It is obvious that factors such as the prevailing correlation among the data, homogeneity of covariance structure, and the selection of optimal components might influence the classifier performance. Probably the prevailing thermo-muscular similarities between the participants' neutral faces and the faces with simulated facial expressions also contributed to the classifier-performance.

When the neutral faces and the faces with intentional expressions of happiness and sadness were classified using the optimal features (Table 3), $12.5 \%$ of neutral faces were confused with the pretended sad faces. During the classification of evoked facial expressions, the neutral faces were not confused with the evoked expressions of happiness or sadness (Table 6). This confusion pattern could be understood in the light of the discussion on emotion-specific thermo-muscular activities.

Wolf and others (2005) reported that Orbicularis Oculi, Mentalis, and Depressor Anguli Oris contribute to the expression of negative emotions. Probably, the quantitative differences in the thermal data measured on a neutral face and those measured on the faces representing evoked sadness helped in reducing the confusion between the neutral and sad faces. Probably, simulating the emotion of sadness did not allow enough thermomuscular activities along the Orbicularis Oculi, Mentalis, and Depressor Anguli Oris and so the simulated sadness was confused with a neutral face.

When the neutral faces and the faces with intentional expressions of sadness and happiness were classified (Table 3), 6.3\% of neutral faces were confused with intentionally happy faces. Studies found that Zygomaticus Major, Orbicularis Oris, Orbicularis Oculi, Mentalis and Platysma contribute to the expression of positive emotional experiences (Iwase et al. 2002; Kall 1990; Root and Stephens 2003; Vrana and Gross 2004). Probably the thermo-muscular system was not fully engaged in the expression of simulated emotions so intentionally happy faces were confused with the neutral faces. However, when emotions were evoked, some thermo-muscular activity took place along these muscles and so the evoked expression of happiness was not confused with the neutral faces.

The intentional expression of sadness was confused with the expression of happiness $(12.5 \%)$, when the neutral faces and the faces with intentionally positive and negative expressions were classified (Table 3). A higher confusion rate was observed between the evoked facial expressions of happiness and sadness as $20 \%$ of evoked expressions of happiness were confused with sad faces (Table 6). However, only $10 \%$ of the evoked sad faces were confused with evoked happiness in Table 6. This confusion pattern could also be examined in the light of emotion-specific thermo-muscular activities. Studies suggested that thermo-muscular activities along Zygomaticus Major, Orbicularis Oris, 
Mentalis and Platysma represent the facial expression of positive emotional experiences (Iwase et al. 2002; Kall 1990; Root and Stephens 2003; Vrana and Gross 2004). The facial expression of negative emotions in reported studies involved Corrugator, Masseter, Triangularis, Orbicularis Oculi Palpabraeous, Platysma, and Bucccinator muscles. Studies have reported some degree of thermo-muscular activity around the Orbicularis in facial expression of both positive and negative emotions (Hess et al. 2000; Iwase et al. 2002; Kall 1990; Vrana 1993). Since 17 of the 75 discovered FTFPs were physically located on Orbicularis, the thermo-muscular activity along this particular muscle could have resulted in the confusion between the facial expression of happiness and sadness.

When the four intentionally positive and negative facial expressions were classified, $18.8 \%$ of the disgusted faces were confused with the angry faces in Table 4. Also, 18.8\% of the angry faces were confused with the disgusted faces. In a vision-based AFEC capable classifier Dubuisson and other (2002) developed, 15\% faces of anger were confused with faces of disgust but less than $04 \%$ faces of disgust were confused with angry faces. When we classified the evoked expressions $20 \%$ angry faces were confused with the disgusted faces but only $10 \%$ of the disgusted faces were confused with the angry faces (Table 6). An examination of the negative emotion specific thermo-muscular activities would explain this confusion pattern. As the studies suggest, the facial expression of aggression and rage involve Corrugator, Masseter, Triangularis, Orbicularis Oculi, Palpabraeous, Procerus Nasi, Labii Inferioris and Platysma (Kall 1990). The expression of sadness and fear, previous works suggest, involve Frontalis, Palpabraeous Superior and Inferioris, Labii Superioris Orbicularis Oculi, Masseter, Triangularis and Bucccinator. As some of these muscles were reportedly involved in the expression of sadness, rage, anger and fear, the similarities between the patterns of thermo-muscular activities around these muscles might have resulted in the observed confusion pattern.

When the neutral faces and faces with six pretended basic facial expressions were classified, the classification results (Table 5) revealed certain similarities between the thermal characteristics of the facial expressions. During the cross validation tests (Table 5 ), the neutral faces were often confused with the pretended sad (18.8\%) and surprised (18.8\%) expressions. Cohen and others (2003) attempted person-independent facial expression classification in a vision-based AFEC system and observed a similar classification and confusion pattern. The neutral faces in their investigation were confused with sadness and surprise. Another vision-based AFEC capable system that (Calder et al. 2001) developed did confuse some $23 \%$ of neutral faces with sad expression and confused around $07 \%$ neutral faces with the faces of surprise. Hence some 
parallels might be drawn between the confusion patterns observed in this investigation and the ones observed in some earlier vision-based AFEC capable systems.

The pretended expressions of happiness in Table 5 were confused with the neutral faces $(12.5 \%)$ and with the faces of surprise $(18.8 \%)$. The vision-based system (Calder et al. 2001) developed confused only $02 \%$ of the neutral faces with the faces expressing happiness. Huang and Huang (1997) also used visual cues for AFEC and reported that their system confused only $02 \%$ of neutral faces with the facial expression of happiness. The pretended expression of anger (Table 5) was often confused with the neutral $(18.8 \%)$ faces. The angry faces were in Table 5 were also confused with the happy (18.8\%) faces. In a system that Cohen and others (2003) developed, around $2.04 \%$ expressions of anger were confused with neutral faces and $4.76 \%$ of angry faces were confused with the happy faces. In another system Huang and Huang (1997) designed, only 04\% faces with the expression of anger were confused with the faces of smile. This confirms that the facial expressions of anger and happiness cause different thermo-muscular and hæmodynamic activities on the face. Consequently, these two facial expressions might have generated different temperature variation patterns along the major facial muscles. Probably, there was very little overlap between the subspaces containing the pretended facial expressions of anger and happiness.

In order to examine the relevance and real life significance of this work, we find it useful compare our thermal features-based classifiers with the visual signal-based classifiers. Essa and Pentland (1997) developed an AFEC capable system using opticalflow analysis to classify the facial expressions of joy, disgust, surprise and anger. Their system correctly classified $98 \%$ faces with the four facial expressions. One of the classifiers we developed during this investigation (Table 4) would correctly classify $67.2 \%$ faces pretending the same facial expressions. Our evoked facial expression classifier (Table 6) was able to correctly classify $72 \%$ neutral faces and faces with evoked expressions happiness, sadness, disgust and anger.

Edwards and others (1998) were able to correctly classified $74 \%$ of the seven facial expressions. Lyons and others (1999) successfully classified $75-92 \%$ faces with the seven facial expressions. Our seven-expression classifier was able to successfully classify only $57.2 \%$ faces.

Our facial thermal features could however recognize some facial thermal features better than the vision-based classifiers cited in the above paragraphs. It became obvious from our classification results that the transient facial thermal features would provide more and better physiological information about some facial expressions than others. 
Studies on human perception of facial expressions suggest that humans do not always correctly recognize the facial expressions of affective states (Ekman 1982). Humans generally do not confuse happiness with other facial expressions. However, humans very frequently confuse the facial expressions of various negative emotions. In particular, humans find it difficult to distinguish between fear and surprise (Ekman 1982). Compare to humans, our seven facial expression classifier (Table 5) was highly successful in classifying the negative facial expression of fear (87.5\% success rate). In Black and Yacoob (1997), 83\% faces of fear were correctly classified. The AFEC system Dubuisson and others (2002) developed confused around $16 \%$ faces of fear with happy faces and over $05 \%$ faces of fear with faces of disgust. Our results suggest that the facial expression of fear causes some significant thermal variations along the major facial muscles. Similarly, our evoked expression classifier (Table 6) could correctly classify $90 \%$ of the sad faces and $70 \%$ faces of disgust. The facial expression of anger could not be classified with a similar degree of success. Probably, the facial expression of anger engages the same FTFPs as the other negative facial expressions would. So just like a vision-base AFEC system, a thermal feature-based AFEC system would frequently confuse the expression of anger with other negative facial expressions.

\section{CONCLUSION}

Breitsprecher and others (2002) studied the functional anatomy of muscles of facial expressions and reported that muscles of facial expressions function as slings. They reported a degree of correlation between the physiological measurements taken on the major facial muscles (Breitsprecher et al. 2002). In our investigations, thermal analysis of the TIV data measured along the major facial muscles on the participant faces also suggested some degree of correlation among the TIV. Thus, the thermal variations along the major facial muscles (and their underlying correlation) might have resulted from the contraction and /or expansion of the muscles during the expression of emotions. Perhaps, the core body reacted to the changes in the affective states in such a way that the rate of heat transfer to and from the facial skin surface got influenced and changed. Perhaps, a change in core body temperature causes some significant and correlated thermal changes under the skin surface at the identified locations (FTFPs) on the face. The classification results suggested that emotion-specific transient facial skin temperature measurements could help distinguish between; neutral and (pretended) happy and sad faces, multiple (pretended) positive and negative facial expressions, and neutral and six (pretended) basic facial expressions. These initial results suggested that emotion specific transient facial thermal features might help in recognizing a wide range of underlying affects along the 
direction of valance. However, the physical locations of the identified discriminator variables obtained from the TIV data measured at the FTFPs suggested that the AFEC and AAR might require monitoring the thermal changes at multiple locations on the face along the major facial muscles.

Though we did not construct a Gaussian mixture model having pretended and evoked facial expressions groups as constituting components, the pretended and evoked facial expression groups seem to have significantly different thermal profiles. However, in order to establish the real differences pertaining to the facial expressions of pretended and naturally evoked emotions, more work is needed. Such an investigation should possibly begin by examining the differences between the thermal profiles of the simulated and evoked facial expressions on an adequate number of same participant faces. Our work however demonstrated some underlying differences in the thermal profiles of pretended and evoked facial expressions. This initial work further suggested that thermal infrared imaging might help in distinguishing between the facial expressions of simulated and evoked emotions.

The observed classification results also reflect upon the computational efficacy of the proposed computational approach. The constructed statistical classifiers consistently achieved excellent classification results on the training vectors. However, the linear discriminant algorithm consistently generalized to new and unknown thermal faces with a comparatively lesser efficiency. Also, some facial expressions were better classified than the others in each classifier test. These observations highlight the influence of a constructed Gaussian mixture model on the performance of the classifier.

This work provides informed answers to the research questions raised in section 1 of this paper. This work, in a broad perspective, suggests the viability of using the emotionspecific transient facial skin temperature measurements in security and surveillance, clinical diagnosis, criminal investigations and human-computer interaction. The future AFEC and AAR capable systems might possibly be able to employ and rely upon the non-invasive, thermal infrared measurements of facial skin temperature.

\section{PROPOSED DIRECTIONS OF FUTURE WORK}

The results of this investigation allowed setting up an agenda for future research on AFEC and AAR using the facial skin temperature. It is recommended that the future investigations focus on the following issues:

1. A finer distinction between the expressions of affective states;

2. Accounting for the individual and group differences in classifying the affective states; and 
3. Extension of the thermal image database.

\subsection{Finer distinction between the facial expressions}

The true nature of relationship between the intensity of emotion and the measurements of thermo-muscular activities has yet to be established. These relationships were not taken into consideration in this work.

Understanding of facial expressions in this work was based on the visual appearance and physiognomy of a face. Three referees were requested to examine and agree on the facial expression of affective states but the underlying relationship between the intensities of emotions and their facial expressions were not known and could not be taken into account. The effect of intensity of emotions on the facial expressions might have influenced the thermo-muscular activities and the facial skin temperature. Also, an observer's personal interpretation of a facial expression could have influenced the data acquisition process. A future investigation should pay more attention to the association between the intensities of emotions and their facial expressions.

From an application point of view, an AFEC system should also be able to distinguish between the pretended and evoked facial expressions and affective states. Further investigation in this direction might result in a better AFEC and AAR functionality and could help other communities such as physicians, psychologists, and criminal investigators.

Use of more sensitive infrared sensors could be another way of achieving a finer distinction. Thermal sensitivity of the infrared detectors mounted on the thermal infrared cameras would influence the discovery of covariance in the acquired thermal data. Recent developments in sensors and micro-machine technologies have resulted in improved thermal sensitivity of infrared detectors. New and more efficient thermal infrared detectors have started to emerge (Phillips 2002). Their better thermal sensitivity would help in feature extraction and selection. It would consequently allow efficient recognition and robust classification of new and unknown thermal facial patterns.

\subsection{Individual differences}

Several researchers have highlighted the importance of examining the differences between various racial, ethnic, and geographically separate groups for designing the AFEC and AAR capable systems. Studies have suggested that muscular structure of people belonging to different ethnic and racial backgrounds might differ. Also, certain muscles present in some groups of individuals might not be present in others (Pessa et al. 1998). Several studies also pointed out the differences between the bio-physiological 
reactions to emotions in men and women (McFarland and Kadish 1991). A future investigation should therefore examine the emotion and facial expressions related biophysiological differences between various racial, ethnic and gender populations.

Another dimension of the individual differences arises from the emotion-specific response difference between some age groups. Studies suggest that bio-physiological reaction to emotions varies and decreases with the age. Influence of age on the emotional reactivity, autonomic responses and the bio-physiological expressions of emotion is not fully understood yet (Kunzmann and Gruhn 2005). Mentally ill people and psychopaths are also believed to have slow and different response to emotion stimuli as compare to neutral people (Pham et al. 2000). Hence, incorporation of the age difference factor in a future work is highly recommended.

Yet another skin related individual difference arises from the facial skin condition. It has been established through scientific investigations that some parts of the facial skin are more severely and frequently affected by skin diseases than others. Diseases such as dermatitis, contact urticaria and seborrheic dermatitis influence the biophysical function of facial skin at these particular parts of the facial skin (Kobayashi and Tagami 2004). Therefore, factors such as stratum corneum should be considered in developing and extending the database of sample infrared images for further investigations.

Another health related issue might also have implications for the future work. The issue was highlighted in studies suggesting that when people imagined happy, sad and angry situations, different patterns of facial muscle activity were observed through electromyography (Schawrtz et al. 1976). These facial expression patterns differ between the depressed and the non-depressed people. This difference in facial expression patterns therefore ads yet another dimension to the future investigation of thermal infrared measurement of the facial expressions.

\subsection{Extended database of thermal images}

Keeping the individual differences between the various population groups in mind, an extended database of sample thermal images should be developed for future investigations. The sample thermal images should include various ethnic, regional, racial, gender and age groups.

An extended database would also provide a robust and reliable parametric estimate of the facial thermal data. A larger population sample would further validate the statistical analyses and the classification results. 


\section{REFERENCES}

ABIDI, B., HUQ, S. AND ABIDI M. 2004. "Fusion of visual, thermal, and range as a solution to illumination and pose restrictions in face recognition," In the Proceedings of the 2004 IEEE International Carnahan Conference on Security Technology, Albuquerque, NM, October 2004, 325-330.

ACHARYA, T., AND AJOY R. 2005. Image Processing: Principles and Applications, London: Wiley Interscience.

ALLANSON J. AND FAIRCLOUGH, S.H. 2004. "A research agenda for physiological computing," Interacting with computers, vol. 16, pp. 857-878.

ANG, L.B.P., BELEN, E.F., BERNARDO, R.A., BOONGALING JR., E.R., BRIONES, G.HH., AND ASTHANA, H.S. AND MANDAL, M.K. 1997. Hemiregional variations in facial expression of emotions. British Journal of Psychology 88, 519-525.

BARTLETT, M.S., HAGER, J.C., EKMAN P., AND SEJNOWSKI, T.J. 1999. Measuring Facial Expressions by Computer Image Analysis. Journal of Psychophysiology 36, 253-263.

BELMONT REPORT. 1979. Ethical principles and guidelines for the protection of human subjects of research, available online: http://ohsr.od.nih.gov/guidelines/belmont.html, United States Government, National Institute of Health, Washington D.C.

BLACK, M.J., AND YACOOB, Y. 1997. "Recognizing facial expressions in image sequences using local parameterized models of image motion," International Journal of Computer Vision, vol. 25, pp. 23-48. BOLLE, R. M., CONNELL, J. H., PANKANTI, S., RATHA, N. K. AND SENIOR A. W. 2004. Guide to Biometrics. Springer, New York, USA

BOULIC, L.E.R. AND THALMANN. D. 1998. Interacting with virtual humans through body actions. IEEE Computer Graphics and Applications 98, 8-11.

BRADLEY, M.M., SABATINELli, D., LANG, P.J., FITZSIMMONS, J.R., KING, W., DESAI, P. 2003. Activation of the visual cortex in motivated attention. Behavioral Neuroscience 117, 369-380.

BREITSPRECHER, L., FANGHÅNEL, A., NOE, A., LOCKETT E., AND RAAB, U. 2002. The functional anatomy of the muscles of facial expression in humans with and without Cleft Lip and Palate: A contribution to refine muscle reconstruction in primary cheilo and rhinoplasties in patients with uni and bilateral complete CLP. Annals of Anatomy, vol. 184, pp. 27-34.

BUSSO, C., DENG, Z., YILDIRIM, S., BUlUT, M., LEE, C.-M., KAZEMZADEH, A., LEE, S., NEUMANN, U., AND NARAYANAN, S. 2004. "Analysis of emotion recognition using facial expressions, speech and multimodal information," In the Proceedings of 6th International Conference on Multimodal Interface, ICMI'04, PA, pp. 205-211.

CALDER, A.J., BURTON, A.M., MILlER, P., YOUNG, A.W., AKAMATSU, S. 2001. “A principal component analysis of facial expressions," Vision Research, vol. 41, pp. 1179-1208.

CANTRONIC SYSTEMS INC. 2001. IR 860 User Manual. Cantronic Systems Inc. Coquitlam, Canada.

CHEN, X., AND HUANG, T. 2003. "Facial expression recognition: A clustering-based approach," Pattern Recognition Letters 24, 1295-1302.

CHRISTIE, I. C. AND FRIEDMAN, B. H. 2004. "Autonomic specificity of discrete emotion and dimensions of affective space: a multivariate approach,” International Journal of Psychophysiology, vol. 51, pp. 143-153. COHEN, I., SEBE, N., GARG, A., CHEN, L.S., AND HUANG, T.S. 2003. "Facial expression recognition from video sequences: temporal and static modeling, "Journal of Computer Vision and Image Understanding, no. 91, pp. 160-187.

COLLET. C., VERNET-MAURY, E., DELHOMME, G., AND DITTMAR, A. 1997. Autonomic nervous system response patterns specificity to basic emotions. Journal of Autonomic Nervous System 63, 45-57.

CRISSEY, J. T., AND PARISH, L. C. 2004. "The red face: Historical considerations," Clinics in Dermatology, vol. 11, no. 2, pp. 197-201.

CRITCHLEY, D., DALY, E.M., BULLMORE, E.T., WILLIAMS, S.C.R., AMELSVOORT, T. V., ROBERTSON, D.M., ROWE, A., PHILliPS, M., MCALONAN, G., HOWLLIN, P. AND MURPHY, D.G.M. 2000. The functional neuroanantomy of social behavior: changes in cerebral blood flow when people with autistic disorder process facial expressions. Brain 123, 203-212.

DeSILVA, L.C., MIYASATO, T. AND NAKATSU, R. 1997. Facial emotion recognition using multimodal information. In the Proceedings of 1997 IEEE information, Communication and Signal Processing Conference 1997, 397-401.

DHEW. 1979. Department of Health, Education and Welfare. Publication No. (OS) 78-0014. US Government Printing Office, Washington, D.C., USA.

DIMBERG, U. 1990a. "Facial electromyography and emotional reactions," Psychophysiology, vol. 27, no. 5, pp. 481-494.

DIMBERG, U. 1990b. "Facial reactions to auditory stimuli: sex differences," Scandinavian Journal of Psychology, vol. 31, no. 3, pp.228-233.

DROR, I.E., PÉRON, A.E., HIND, S.L., AND CHARLTON, D. 2005. When emotions get better of us: The effect of contextual top-down processing on matching fingertips," Applied Cognitive Psychology, vol. 19, pp. 799-809.

DUBUISSON, S., DAVOINE F., AND MASSON, M. 2002. A solution for facial expression representation and recognition. Signal Processing: Image Communication 17, 657-673.

DUDA, R.O., HART, P.E. AND STORK, D.G. 2001. Pattern Classification. Wiley Interscience, New York, USA. 
EDWARDS, G.J., COOTES, T.F. AND TAYLOR, C.J. 1998. Face recognition using active appearance models. In the proceedings of the European Conference on Computer Vision, vol. 2, pp. 581-595.

EKMAN, P. 1982. Emotion in the Human Face. Cambridge University Press, England.

EKMAN, P., DAVIDSON, R.J. AND FRIESEN, W.V. 2000. "Duchenne's smiles: Emotional expression and their brain physiology II," Journal of Personality and Social Psychology, vol. 58, pp.342-353.

EKMAN, P., LEVENSON, R.W. AND FRIESEN, W.V. 1983. Autonomic nervous system activity distinguishes among emotions. Science 221, 1208-1210.

ESSA, I. and PENTLAND, A. 1997. Coding, analysis, interpretation and recognition of facial expressions. IEEE Transactions on Pattern Analysis, Machine Intelligence 19, 757-763.

EVELAND, C.K., SOCOLINSKY, D.A., AND WOLF, L.B. 2003. "Tracking human faces in infrared video, Image and Vision Computing, vol. 21, no. 7, pp. 579-590.

EVERITT B.S., AND DUNN, G. 1991. Applied Multivariate Data Analysis, John Wiley and Sons, London.

FUJIMASA, I. 1998. Pathophysiological expression and analysis of infrared thermal images. IEEE Engineering in Medicine and Biology 17, 34-42.

FUJIMASA, I., CHINZEI, T., AND SAITO, I. 2000. "Converting far infrared image information to other physiological data," IEEE Engineering in Medicine and Biology, vol. 19, no. 3, pp. 71-76.

GARBEY, M., MERLA, A. AND PAVLIDIA I. 2004. Estimation f blood flow speed and vessel location from thermal video. In the Proceedings of CVRP 2004-IEEE 2004 Conference on Computer Vision and Pattern Recognition 1, Washington DC, 1356-1363.

GONZALEZ, R.C., AND WOODS, R.E. 2002. Digital Image Processing. Addison-Wesley, New York.

HEALEY, J.A. AND PICARD, R.W. 2005. Detecting stress during real-world driving tasks using physiological sensors. IEEE Transactions on Intelligent Transportation Systems 6, 156-166.

HERRY, C.L., AND FRIZE, M. 2002. "Digital processing techniques for the assessment of pain with infrared thermal imaging," In the Proceedings of the 2002 IEEE International Conference on Engineering in Medicine and Biology, IEEE EMBS 2002, pp. 1157-1158, Houston, October 23-26.

HESS, U., KAPPAS, A., MCHUGO, G.J., LANZETTA, J.T., AND KLECK, R.E. 1992. "The facilitative effect of facial expression on self-generation of emotion," Psychophysiology, vol. 12, no.3, pp. 251-265.

HUANG, C., AND HUANG, Y. 1997. "Facial expression recognition using model-based feature extraction and action parameters classification," Journal of Visual Communication and Image Representation, vol. 8, no. 3, pp. 278-290.

IAPS. 1997. "International affective picture system technical manual and affective ratings," available online. http://www.unifesp.br/adap/instructions.pdf.

IWASE, M., OUCHI, Y., OKADA, H., YOKOHAMA, C., NOBEZAWA, S., YOSHIKAWA, E., TSUKADA, H., TAKEDA, M., YAMAGGUTI, K., KURATSUNE, H., SHIMIZU A., AND WATANABE, Y. 2002. Neural substrates of human facial expression of pleasant emotion induced by comic films: a PET study. Neuroimage 17, 758-768.

JIANG, G. AND LE, K. 2007. Character Analysis of facial expression image. In the Proceedings of the CME 2007, IEEE/ICME International Conference on Complex Medical Engineering, 23-27 May 2007, Beijing, China, 824-827.

JOLLIFFE, I.T. 2002. Principal Component Analysis, New York, Springer-Verlag.

JONES B.F., AND PLASSMANN, P. 2002. Digital infrared thermal imaging of human skin. IEEE Engineering in medicine and biology $21,41-48$

JONES, B.F. 1998. A reappraisal of use of infrared thermal image analysis in medicine. IEEE Transactions on Medical Imaging 17, 1019-1027.

JONES, C. H., RING, E. F. J. AND CLARK, R. P. 1988. Medical Thermography. In Applications of Thermal Imaging, BURNAY, S. G., WILliAMS, T. L. AND JONES, C. H. N., Eds. Adam Hilger, Bristol, 156-187.

KAKADIARIS, I.A., PASSALIS, G., THEOHARIS, T., TODERICI, G., KONSTANTINIDIS, I. AND MURTUZA, N. 2005a. 8D-THERMO CAM: Combination of geometry with physiological information for face recognition. In the Proceedings of the CVPR 2005, IEEE Computer Society Conference on Computer Vision and Pattern Recognition 2, June 2005, San Diego, CA 1183-1188.

KAKADIARIS, I.A., PASSALIS, G., THEOHARIS, T., TODERICI, G., KONSTANTINIDIS, I., AND MURTUZA, N. 2005b. Multimodal face recognition: Combination of geometry with physiological information. In the Proceedings of the CVPR 2005, IEEE Computer Society Conference on Computer Vision and Pattern Recognition 2, June 2005, San Diego, CA, 1022-1029.

KALL, R. 1990. "Emotional self regulation and facial expression muscle measurement and training," in Clinical EMG for surface recording, vol. 2, J.R. Cram and J.V. Basmalian (Eds.), 1990, Clinical Resources, Nevada City, CA.

KHAN, M.M. 2008. "Cluster-analytic classification of facial expressions using infrared measurements of facial thermal features," Ph.D. Thesis, Department of Computing and Engineering, University of Huddersfield, Huddersfield, England.

KHAN, M.M., INGLEBY, M., AND WARD, R.D., (2006) "Automated facial expression classification and affect interpretation using infrared measurement of facial skin temperature variation," ACM Transactions on Autonomous and Adaptive Systems, Vol. 1, No. 1, pp. 91-113.

KHAN, M.M., WARD, R.D. AND INGLEBY, M. 2004. Automated classification and recognition of facial expressions using infrared thermal imaging. In the Proceedings of 2004 IEEE Conference on Cybernetics and Intelligent Systems, Singapore, December 2004, 202-206. 
KHAN, M.M., WARD, R.D., AND INGLEBY, M. 2005. Distinguishing facial expressions by thermal imaging using facial thermal feature points. In the Proceedings of 19th British HCI Group Annual Conference HCI 2005, September 2005, Edinburgh, L. MACKINNON, O. BERTELSEN AND N. BRYANKINNS, Eds. British Computer Society, Scotland, 10-14.

KIM, H.K., BANG, S.W. AND KIM S.R. 2004. Emotion recognition system using short-term monitoring of physiological signals. Medical and Biological Engineering and Computing 42, 419-427.

KINNEAR, P.R., AND GRAY, C.D. 2000. SPSS for Windows made simple. Psychology Press Ltd., East Sussex, England.

KOBAYASHI, H. AND TAGAMI, H. 2004. "Distinct locational differences observable in biophysical functions of the facial skin: with special emphasis on the poor functional properties of the stratum corneum of the perioral region," International Journal of Cosmetic Science, vol. 26, pp. 91-101.

KONG, S.G., HEO, J. ABIDI, B.R., PAIK, J., AND ABIDI, M.A. 2005. Recent advances in visual and infrared face recognition-a review. Computer Vision and Image Understanding 97, 103-135.

KUNZMANN, U., AND GRUHN, D. 2005. Age differences in emotional reactivity: the sample case of sadness. Psychology and Aging 20, 47-59.

KURSE, P.W. 2001. Uncooled Thermal Imaging: Analysis, Systems and Applications. SPIE Press,

LISETTI, C.L.AND NASOZ, F., 2004. Using noninvasive wearable computers to recognize human emotions from physiological signals. EURASIP Journal of Applied Signal Processing 11, 1672-1687.

LYONS, M., BUDYNEK J., AND AKAMATSU, S. 1999. Classifying images of facial expression using a Gabor wavelet representation. In the Proceedings of $2^{\text {nd }}$ International Conference on Cognitive Science, Tokyo, Japan, 1999, pp. 113-118

MATSUZAKI, H. AND MIZOTE, M. 1996. Measurement of facial temperature fluctuations by thermal image analysis. Progress in Biophysics and Molecular Biology 65, 185-186.

McFARLAND, R.A., AND KADISH, R. 1991. Sex differences in finger temperature response to music. International Journal of Psychophysiology 11, 295-298.

McGIMPSEY, J.G., VAIDYA, A., BIAGIONI, P.A. AND LAMEY, P.-J. 2000. Role of thermography is the assessment of infraorbital nerve injury after malar fractures. British journal of Oral and Maxillofacial Surgery 38, 581-584.

McLACHLAN, G. J., 2004. Discriminant Analysis and Statistical Pattern Recognition, New Jersey, Wiley. MURPHY, S.T. AND ZAJONC, R.B. 1993. "Affect, cognition and awareness: affective priming with optimal and suboptimal stimulus exposures," Journal of Personality and Social Psychology, vol. 64, pp. 723739.

NAEMURA, A., TSUDA, K., AND SUZUKI, N. 1993. Effects of loud noise on nasal skin temperature. Originally published in Japanese, translation available. Shingrigaku Kenkyu 64, 51-54.

NAKAYAMA, K., GOTO, S., KURAOKA K., AND NAKAMURA, K. 2005. Decrease in nasal temperature of rhesus monkeys (Macaca mulatta) in negative emotional state. Journal of Physiology and Behavior 84, 783-790.

NIEDENTHAL, P.M., HALBERSTADT, J.B., MARGOLIN, J. AND INNES-KER, A.H. 2000. "Emotional state and the detection of change in facial expression of emotion," European Journal of Social Psychology, vol. 30, pp. 211-222.

OGASAWARA, T., KITAGAWA, Y., OGAWA, T., YAMADA, T., KAWAMURA, Y. AND SANO, K. 2001. MR Imaging and Thermography of facial angioedema: A case report. Oral Surgery, Oral Medicine, Oral Pathology 92, 473-476.

OLIVIER, B., ZETHOF, T., PATTIJ, T., VAN BOOGAERT, M., VAN OORSHOT, R., LEAHY, C., OOSTING, R., BOUWKNECHT, A., VEENING,J., VAN DER, GUGTEN, AND GROENINK, L. 2003. Stress-induced hypothermia and anxiety: pharmacological validation. European Journal of Pharmacology 28, 117-132.

OTSUKA, K., OKADA, S., HASSAN, M., TOGAWA, T. 2002. "Imaging of skin thermal properties with estimation of ambient radiation," IEEE Engineering in Medicine and Biology, vol. 21, no. 6, pp. 49-55.

PALOMBA, D., SARLO, M., ANGRILli, A., MINI, A., STEGAGNO, L. 2000. Cardiac responses associated with affective processing of unpleasant film stimuli. International Journal of Psychophysiology 36, 45-57.

PARTALA, T., SURAKKA, V. AND VANHALA, T. 2006. Real-time estimation of emotional experiences from facial expressions. Interacting with Computers 18, 208-226.

PAVLIDIS I. AND LEVINE, J. 2002. "Thermal image analysis for polygraph testing," IEEE Engineering in Medicine and Biology 21, 56-64.

PAVLIDIS, I. 2004. Lie detection using thermal imaging. In Proceedings of SPIE - Thermosense XXVI, Conference of the International Society for Optical Engineering, April 2004, Orlando, FL, SPIE, Bellingham, USA, 270-279.

PESSA, J., ZADOO, V., GERZA, P., ADRIAN, E.J., DEWITT, A., AND GARZA, J. 1998. Double or bifid zygomatcius major muscle: anatomy, incidence and clinical correlation. Journal of Clinical Anatomy 11 , 310-313.

PHAM, T.H., PHILIPPOT, P., RIME, B. 2000. Subjective and autonomic responses to emotion induction in psychopaths. Encaphale 26, 45-51.

PHILLIPS, T.J. 2002. High performance thermal imaging technology. Advanced Semiconductor Magazine 15, 32-36.

PICARD, R.W. 2000. Affective Computing. MIT Press, Cambridge, MA. 
PIZZAGALli, D., KOENIG, T., REGARD, M. AND LEHMANN, D. 1998. Faces and emotion: brain electric field sources during covert emotional processing. Neuropsychologia 36, 323-332.

POLLINA, D.A., DOLLINS, A.B., SENTER, S.M., BROWN, T.E., PAVLIDIS, I., LEVINE, J.A., AND

RYAN, A.H. 2006. "Facial skin surface temperature changes during a concealed information test," Annals of Biomedical Engineering, vol. 34, no. 7, pp. 1182-1189.

POSAMENTIER, M.T. AND ABDI, H. 2003. Processing faces and facial expressions. Neuropsychology Review 13, 113-143.

PROKOSKI, F.J. AND IEDEL, R. 1999. Infrared identification of faces and body parts. In Biometrics: Personal Identification in Networked Society. JAIN, A.K., BOLLE, R.M. AND PANKANTI, S., Eds. Kulwer Academic Press, Boston, 191-212.

PURI, C., OLSON, L., PAVLIDIS, I., LEVINE J., AND STARREN, J. 2005. StressCam: Non-contact measurement of users' emotional states through thermal imaging. In the Proceedings of the CHI 2005, April 2005, Portland, Oregon, 1725-1728.

RIMM-KAUFMAN, S.E., AND KAGAN, J. 1996. "The psychological significance of changes in skin temperature," Motivation and Emotion, vol. 20, pp. 63-78.

ROOT, A.A., AND STEPHENS, J.A. 2003. "Organization of the central control of muscles of facial expression in man," The Journal of Physiology, vol. 549, pp. 289-298.

SARLO, M., BUODO, G., POLI, S., AND PALOMBA, D. 2005. Changes in EEG alpha power to different disgust elicitors: the specificity of mutilations. Neuroscience Letters 382, 291-296.

SCHWARTZ, G.E, FAIR, P.L., SALT, P., MANDEL, M.R. AND KLERMAN, G.L. 1976. Facial muscle patterning to affective imagery in depressed and non-depressed subjects. Science, New Series 192, 489-491. SCHWARZ, S., HOFMANN, M.H., GUTZEN, C., SCHLAX S., AND EMDE, VON DER G. 2002. "VIEWER: a program for visualizing, recording, and analyzing animal behavior, Computer Methods and Programs in Biomedicine, no. 67, pp. 55-66.

SHARMA, S. 1996. Applied Multivariate Techniques. Wiley, New York.

SINHA, R. AND PARSON, O. 1996. "Multivariate response patterning of fear and anger," Cognition and Emotion, vol. 10, no. 2, pp. 173-198.

SOCOLINSKY, D.A., SELINGER, A., AND NEUHEISEL, J.D. 2003. "Face recognition with visible and thermal infrared imagery," Computer Vision and Image Understanding, vol. 91, pp. 72-114.

SUGIMOTO, Y., YOSHITOMI, Y. AND TOMITA, S. 2000. A method of detecting transitions of emotional states using a thermal facial image based on a synthesis of facial expressions. Robotics and Autonomous Systems 31, 147-160.

TIAN, Y.L., KANADE, T. AND COHN, J. 2002. Evaluation of Gabor-Wavelet based facial action unit recognition in image sequence of increasing complexity. In the Proceedings of the 5th IEEE International Conference on Automatic Face and Expression Recognition (FG'02), May, 2002, Washington DC, 229-234. TOIVANEN, J., VÅYRYNEN, E., AND SEPPÅNEN, T. 2004. "Automatic discrimination of emotions in spoken Finnish," Language and Speech vol. 47, no. 4, pp. 383-412.

VIANNA, D.M., AND CARRIVE, P. 2005. Changes in cutaneous and body temperature during and after conditioned fear to context in the rat. European Journal of Neuroscince 21, 2505-2512.

VRANA, S.R. 1993. "The psychophysiology of disgust: differentiating negative emotional contexts with facial EMG," Psychophysiology, vol. 30, no.3, pp. 279-286.

VRANA, S.R., AND GROSS, D. 2004. "Reactions to facial expressions: effects of social context and speech anxiety on response to neutral, anger and joy expressions," Biological Psychology, vol. 66, no. 1, pp. 63-78. Webb, A.R. 2002. Statistical Pattern Recognition, London: John Wiley.

WHITESIDE, S. 1998. In the Proceedings of ICSLP 1998:International Conference on Spoken Language Processing, November-December, 1998, Sydney, Australia, pp.699-703.

WILD, B., ERB, M. AND BARTELS M. 2001. "Are emotions contagious? Evoked emotions while viewing emotionally expressive faces: quality, quantity, time course and gender differences," Psychiatry Research, vol. 102, pp. 109-124.

WOLF, K., RAEDLER, T., HENKE, K., KIEFER, F., MASS, R., QUANTE, M., AND WIEDEMANN, K. 2005. "The face of pain- a pilot study to validate the measurement of facial pain expression with improved electromyogram method," Pain Research and Management, vol. 10, no. 1, pp. 9-14.

WRIGHT, P., HE, G., SHAPIRA, N.A. 2004. GOODMAN, W.K., AND LIU, Y., Disgust and the insula: fMRI responses to pictures of mutilation and contamination. NeuroReport 15, 2347-2351.

YOSHITOMI, Y., KIM, S.I., KAWANO, T. AND KITAZOE, T. 2000. Effects of sensor fusion for recognition of emotional states using voice, face image and thermal image of face. In Proceedings of the IEEE International workshop on Robotics and Human Interactive Communication, Osaka, Japan, September 2000, 178-183.

ZAJONC, R.B. 1985. "Emotion and facial efference: a theory reclaimed," Science, vol. 228, pp. 15-21. 